\title{
Some observations on informed consent in non-therapeutic research
}

\author{
J C Garnham Department of Clinical Pharmacology, St Bartholomew's Hospital, \\ West Smithfield, London
}

The quality of the consent obtained from $4 I$ volunteer subjects in eight experiments is evaluated. Five subjects (all physicians) gave informed consent; 22 subjects gave partially informed consent; and 14 subjects merely gave consent.

It is argued that 'informed' consent is obtainable only from medically trained people, and that lip service to this concept in laymen should cease. The concept of medical competence should instead be introduced and a personal medical referee appointed to adjudicate on behalf of the volunteer.

Clinical research has grown in sophistication as well as in the amount undertaken as recent years have brought advances in medicine and an increase in the number of effective drugs available. During this period great interest has been shown in the ethical principles governing medical research which is due in part to the changing circumstances of today and in part to 'other' factors. The BMA booklet on medical ethics (1974) summarizes the situation by stating that 'the lapses from the Hippocratic ideal on the part of the profession in certain countries during the Second World War and the perpetration of crimes against the individual in the name of race or religion have shown the need for a modern restatement of the Oath and a reawakening of the sense of the high calling and the ethical responsibilities of the doctor'.

\section{The literature of medical ethics}

A large body of literature on ethics has been produced, ranging from books by individuals such as Henry K. Beecher (1970) to essays by groups such as Daedalus (a collection of contributions from members of the American Academy of Arts and Sciences, 1969) to reports of the proceedings of conferences and meetings such as those of the New York Academy of Sciences meeting (1969). In addition to books, many ethical 'codes' have been enunciated by individuals, for example, Bradford Hill (1963) and Beecher (1966), and by professional (American Medical Association, 1959; Public Health Council of the Netherlands, 1957; National Institutes of Health, I968; Medical Research Council, 1962-1963), religious (Catholic Hospitals Association, 1955), military (United States Army, 1962), university (Harvard University Health
Services, 1963), international (World Medicah్ Association, I948; World Medical Association 2 , 1949; World Medical Association, 1964; UnitedP Nations, 1958) and governmental (Food and Drug Administration, 1966; Nuremberg Military Tri bunal, 1946-1949) bodies.

\section{The present series of experiments}

Much of the intent of this literature is devoted to $\overrightarrow{0}$ considering what is meant by the consent of the individual taking part as a volunteer in clinical. research. It is on this point that most of the ethicals codes falter, and they fail because they use sucle terms as 'true', 'informed' or 'understanding' to्ठ qualify the word consent, resulting in internationalls accepted codes which are more honoured by breaches than by adherence to the concept the $\overrightarrow{\mathrm{YO}}$ seek to convey. Because of the importance of thist subject it was decided to evaluate the nature of the consent obtained from healthy volunteer subjest who would be taking part in a series of experiments starting in 1971. The consent was to be explicitli obtained 'after adequate explanation.... [to] aक adult of sound mind and understanding ... ? which, the MRC states (Medical Research Councilo I963), 'can be relied upon to be true consent'. The detailed results of these studies have been publishe elsewhere.

\section{The volunteers}

The need for 70 volunteer subjects for eight separate studies was filled by $4 \mathrm{I}$ people, that is several people volunteered for more than one study? The volunteers are described in table $I$.

\section{The nature and design of the studies}

The nature of the eight studies with details of theip duration and the necessary commitments by the volunteers are shown in table II. The term 'session is used to denote one appearance at which the subject took the medication under study. This might necessitate the subject spending one day (the minimum period) for each session at the hospital (a in the sulphadiazine study) or one whole day pluig three daily repeat visits (as in the diftalone study $\Phi$ Briefing and clinical examination sessions have not been included.

Rule 7 of the Nuremberg Code states: 'Prope्f 
TABLE I Occupation and sex of normal volunteers ${ }^{1}$

\begin{tabular}{lll}
\hline Occupation & Female & Male \\
\hline Post workers & I & I2 \\
Pharmacist & I & \\
Medical students & & 5 \\
Dental student & I \\
Anatomy demonstrator & & I \\
Clinical pharmacologists & & 3 \\
Research physician & & I \\
Laboratory technicians & I & 2 \\
Biochemist & & I \\
Pharmacologists & 2 & \\
Medical photographer & & I \\
Mathematician & & I \\
EEG technicians & 2 & 3 \\
Respiratory technician & & I \\
Research chemist & & 2
\end{tabular}

Total $7+34=4 \mathrm{I}$

${ }^{1}$ The ages ranged from 19 to 62 years; mean of $31.88 \pm$ SD 12.05 years

preparations should be made and adequate facilities provided to protect the experimental subject against even remote possibilities of injury, disability or death'. First aid emergency equipment (including a laryngoscope, endotracheal tubes, an inflating bladder, etc, as well as a supply of parenteral emergency drugs such as adrenaline, antihistamines, steroids, etc) is kept in an emergency box in the department. The hospital resuscitation team is always on call for the hospital. An emergency call to this team is answered by the duty registrar followed by the resuscitation trolley on which there is an electrocardiograph and defibrillator. An unrehearsed 'test' call was made at $2.05 \mathrm{pm}$ one afternoon. Four minutes later the doctor responsible for resuscitation arrived in the department. Thus there are always medical personnel and emergency equipment immediately available, with a fully trained, experienced and well equipped resuscitation team available within a few minutes.

Those of the potential subjects who were available and interested had the study explained to them in detail by means of an information sheet which contained a description of the study in which a section was devoted to possible side effects. The information sheet was written in terms thought appropriate to the medical knowledge of the subjects, who were given the opportunity to question the clinician about the experiment and he answered any questions. If the subject agreed to participate he was then asked to sign a consent form. Every attempt was made to fulfil scrupulously the MRC term 'adequate explanation' to adults of 'sound mind and understanding' which they state 'can be relied upon to be true consent'.

The information sheet for the ro volunteers taking part in the quinine experiment included then following paragraph on side effects:

'When used for malaria it (quinine) is given by mouth in a $600 \mathrm{mg}$ dose, three times daily, for seven days or more. When given in consecutive doses over a period of days certain undesirable side effects can occur, such as ringing in the ears, headache,

TABLE II Summary of the present series

\begin{tabular}{llll}
\hline $\begin{array}{l}\text { Study Name } \\
\text { No. }\end{array}$ & $\begin{array}{l}\text { Number of 'sessions' required } \\
\text { for each volunteer }\end{array}$ & $\begin{array}{l}\text { Duration } \\
\text { of study }\end{array}$ & $\begin{array}{l}\text { Number of volunteers } \\
\text { participating }\end{array}$ \\
\hline I Quinine crossover & 10 & I year & 10 \\
2 Sulphadiazine crossover & 3 & 8 weeks & 6 \\
3 Aspirin crossover & 2 & 5 weeks & 10 \\
4 Indomethacin crossover & 2 & 4 weeks & 10 \\
5 Aspirin + indomethacin & I & 2 weeks & 10 \\
6 Rifampicin/isoniazid crossover & 5 & 5 weeks & 10 \\
7 Trimethoxybenzoyl-isoxazolidine & 3 & 8 weeks & 6 \\
8 Diftalone & 5 & Io weeks & 8
\end{tabular}

I-4, 6 and 8 are pharmacokinetic or comparative bioavailability studies; 2) Garnbam, J C, Raymond, K, Shotton, E, and Turner, P, I973a; 3) Garnham, J C, Hicks, D C, Raymond, K and Shotton, E, I973b; 4) Garnham, J C, Raymond, K, Shotton, E and Turner, P, 1975; 5) is an interaction study (Garnham, J C, Raymond, K, Shotton, E and Turner, $P, 1975) ; 7$ ) is an EEG comparative study. 
nausea or disturbed vision. Some people are especially sensitive to this drug, or, in other words, "allergic" to it, and the above symptoms can appear after a single dose of quinine; such people may also suffer from flushing of the skin, itching and skin rashes. Very rarely it may also cause blood in the urine, but this apparently only in pregnant women or in people with malaria. People suffering from these reactions due to quinine have been found in this country after drinking a "gin and tonic" or using some of the preparations such as shampoos.'

(Earlier in the information sheet it was pointed out to the volunteers that 'tonic' water contains quinine as do some shampoos.)

All of these volunteers worked with us for a year. They were all post office workers and most of them belong to the post office group of first-aid workers of the St John's Ambulance Brigade. Thus even though they are classified in the results section as 'laymen' their average amount of medical knowledge would almost certainly be higher than that in the general population. Furthermore, nine out of the ro had taken part as volunteer subjects in previous studies with another investigator. At the end of the year we wished to undertake another study with sulphadiazine and the ro volunteers were asked if they would participate in a further unspecified, shorter study. Four of these declined because three were changing jobs, shift times or place of work, and one because he wanted 'a rest' from being a volunteer subject for a few months. An information sheet was given to the six remaining, in which a deliberate attempt was made to emphasize the side effects in the following way:

\section{Emphasis on side effects}

'Undesirable effects of sulphonamides (side effects) can occur. These can be classified under the following headings:

\section{I) BLOOD}

Sulphonamides can cause the blood cells to break down, causing anaemia, vomiting and jaundice. It is said to occur about five times in every 10 000 patients treated with a full course.

A disappearance of the cells in the blood which fight infection can also occur in about one in one thousand patients on this drug. Most of these cases develop after Io days but before six weeks of continuous medication.

\section{2) URINARY TRACT}

Damage to the kidneys can occur from the sulphonamides by crystals of the drug forming in this organ. This is very unlikely to occur in the present experiment, provided you drink plenty of water in the evening before the experiment and on the morning of each session. Rarely, there may be an allergic reaction by the kidney, when the kidneys stop producing urine.
3) BLOOD VESSELS

Rarely during the course of sulphonamide ad ministration a kind of inflammation of the bloof vessels occurs. Sometimes red itchy lumps on the legs can occur on sulphonamide treatment in. patients suffering from tuberculosis and othese diseases which had previously been undiagnosed.

\section{4) SKIN}

Many kinds of skin rash can be caused by sulpho $\$$ namides as well as an abnormal sensitivity to the sun. These occur most often after seven days of treatment, but can occur earlier in people wh 8 have previously become sensitized to the drug. The same may be said about drug fever which is a more common manifestation of sulphonamide treatment However, it is thought that the occurrence of drug. fever and skin eruptions is related to the quantitio of drug administered, and is least likely to developt if the daily dose of the drug is below $2 \mathrm{~g}$ (we wiho will be using $\mathrm{Ig}$ ).

5) LIVER

Severe liver damage may occur, the developmente of which is not influenced by the dose of the drug: Damage to the liver may increase even after the drug is stopped.

As you can see, some very unpleasant side effects? are possible with this drug, but are extremily unlikely to occur under the conditions of ging experiment'.

At the question session, the questions abouf side effects were answered and it was explaine that progressive severe liver damage could resul in death.

At the end of the sulphadiazine study each sub을 ject was questioned frankly as to why he had participated in a study where possible side effects could be sufficiently serious as to cause death. The were also questioned regarding their understanding of the various side effects.

For the other six experiments (3-8, table II paragraphs describing possible side effects were made as objective as possible, as were the answers to questions, and the language was tailored as fap as possible to the expected medical knowledge of the particular group of volunteers (the occupation? of the volunteers for this study were five preclinica $\bar{b}$ medical students, one preclinical dental student, two pharmacologists, one senior technician and on anatomy demonstrator. For example, the following section appeared in the aspirin information sheet: 0

'Adverse effects of aspirin may be divided inte two categories. Firstly, those which are dosह్ related and which get worse as the blood level of aspirin rises, and secondly, allergic adverse reactions.0

\section{DIRECT TOXIC MANIFESTATIONS}

These usually occur only after multiple high dosag and consist of tinnitus, disturbances of vision 
vertigo, confusion, sweating, hyperventilation and vomiting. The effects on the central nervous system can progress to delirium and convulsions. Dyspepsia is probably due to direct action of the drug although the other gastrointestinal symptoms are related to the blood level. Other side effects which can occur are a bleeding tendency and hyperglycaemia.

\section{ALLERGIC REACTIONS}

These can be acute anaphylaxis, involving swelling of the tongue, lips, face, etc, with a fall in blood pressure or may be manifested as a skin reaction which may look like eczema or acne. Allergic reactions to aspirin probably occur in about two people out of every thousand. Skin disorders are not usually seen unless medication is continued for Io days or more. It is important that if you ever had swelling of the lips or tongue or any skin troubles after taking aspirin or any "cold" preparations that you should tell me when we meet for the first time.'

During or at the end of each of these six experiments each subject was questioned to ascertain their 'proper understanding of the possible nature and consequences' of the experiment. At some convenient and appropriate time after consent was obtained, such as while examining the subject, or preparing to draw blood, the study and possible side effects were discussed. On an individual basis the subject's understanding was explored until a decision was reached in answer to the question, 'Did the person concerned fully understand the possible implications to himself of all the risks?' Yes or no was an acceptable answer. Where a volunteer fell into the 'no' group, questioning was continued to ascertain whether the failure was one of understanding technical details or a failure to understand possible medical and social consequences. This questioning had to be undertaken in such a way that the subject was unaware of the reasons for it because this was a continuous project and some of the volunteers worked in the research department concerned and could bias future studies. Despite these precautions several of the participants (two electroencephalography technicians, one biochemist and a neurophysiologist) realized that more than ordinary efforts were being made with regard to supplying information and obtaining consent.

\section{Consent form}

The consent form was as follows:

I, have had the nature and the possible hazards of the (name of study) study explained to me. I understand these and agree to take part in the experiment as a volunteer subject.

(signature). Date.

\section{The quality of 'consent' obtained}

To us the word 'informed' when used with 'consent' in this context implies a full and understanding appreciation of the possible risks of an experiment, and the knowledge and insight of what the realization of such risks and their consequences would mean to the subject, his family and associates. Despite making more than average efforts to ensure informed consent it was achieved in this series of experiments in only five people - three clinical pharmacologists, an anatomy demonstrator, and a research physician.

In the 22 volunteers working in disciplines related to medicine there was 'partially informed' consent, a designation which was given when it was found that the volunteer knew technically what was meant by the description of the side effects but did not fully understand the possible medical and social consequences.

With the 14 laymen, there was merely consent. A volunteer was placed in this category when it was found that he did not understand the nature of all or some of the possible side effects. In some instances, as with the first-aid workers, the terminology was known but there was little understanding of the meaning of the words.

Of the six volunteers who worked with out team for over a year in the quinine and sulphadiazine experiments, not one had really appreciated the possible consequences of severe liver damage. The reasons given by these subjects for joining in the study despite the stated dangers were summarized well by the comment of one of them, 'Doctor, we know you wouldn't hurt us and anyway the hospital wouldn't let you'!

\section{Codes of ethical procedure}

Until I946 codes of ethical procedure concerning human experimentation left the term 'consent' unadorned or qualified it with easily understood words such as 'voluntary'. The attempts to qualify the term 'consent' with words implying that the subject has to have a full and proper understanding of the nature, procedure and risks of proposed experiments first appeared in profusion in 1946 and later. A brief consideration of four of the most respected of these codes will show that even these attempts have clouded rather than cleared the issue.

\section{THE NUREMBERG CODE}

The Nuremberg Code arose from the world's condemnation of certain experiments which happened during the Second World War, and which were brought to light in the Nuremberg Trials. The code is a list of ro principles to which any investigator should adhere. They seem at first glance very reasonable and sensible but if taken literally would make non-therapeutic human experimentation impossible. For example, in rule $I$ it is stated that 
'the person involved should have legal capacity to give consent; should be so situated as to be able to exercise free power of choice, without the intervention of any element of force, fraud, deceit, duress, overreaching, or other ulterior form of constraint or coercion; and should have sufficient knowledge and comprehension of the elements of the subject matter involved as to enable him to make an understanding and enlightened decision'. It has been argued (Parsons, 1969), and probably correctly, that only medically trained people can competently judge the therapeutic effects or dangers of certain procedures. Our experience supports this contention.

\section{THE DECLARATION OF GENEVA}

In 1948 the World Medical Association produced the Declaration of Geneva, in which there is no mention of informed consent. There is, however, the following statement: 'Any act or advice which could weaken the physical or mental resistance of a human being may be used only in his interests'. This sentiment is expressed again in the statement from the General Assembly of the World Medical Association at its meeting in London in 1949: 'Under no circumstances is a doctor permitted to do anything that would weaken the physical or mental resistance of a human being except from strictly therapeutic or prophylactic indications imposed in the interests of his patient'. Almost all non-therapeutic human experimentation could weaken physical or mental resistance, that is, be a risk, 'could' meaning in this instance 'might be able to'. Thus by this international code of medical ethics non-therapeutic clinical research is apparently forbidden, and this precept was not changed at the I968 meeting of the World Medical Association which amended the Declaration of Geneva.

It is sometimes argued that drug research on healthy volunteers is not unlike a clinical trial where it can be maintained that the work is done in the patient's 'general interest' because 'anyone may fall sick and need medicines'. This idea is not only in direct opposition to all ethical considerations (see above) but the MRC go so far as to state, 'It should be clearly understood that the possibility or probability that a particular investigation will be of benefit to humanity or to posterity would afford no defence in the event of legal proceedings'.

It has been further suggested that where possible risks are quite horrifying and exceedingly rare that they should not be discussed because it might attract the masochistic type of volunteer or might unbalance the information.

The example put forward by proponents of this idea goes as follows: 'If all the nasty things were stated that had ever happened to anyone who crossed a street it is very likely that the information offered to would-be street crossers would be so biased as to mislead them actively away from a true concept of the risks which were open to them'. I England and Wales in 1973 there were 85748 people killed or seriously injured on the roads (Department of the Environment, 1975). Th, concept of not mentioning horrifying risks on the basis that it might attract masochists as voluntee $\overline{\bar{\beta}}$ contravenes the spirit of all the codes mentioned in this paper.

THE DECLARATION OF HELSINKI The same body - the World Medical Association $\stackrel{\circ}{g}$ was responsible in 1964 for the Declaration of Helsinki which recognized the need for non therapeutic research and condoned this activit $\vec{y}$ which had been virtually forbidden in 1948 and would again be forbidden four years later (1968) The last section of the Declaration of Helsinki again contains problems over the question of consent. In Section III, entitled 'Non-therapeutic clinical research', are the following rules:

3a Clinical research on a human being cannot be undertaken without his free consent, after he has been fully informed; if he is legally incompeterg the consent of the legal guardian should be procured.

$3 \mathrm{~b}$ The subject of clinical research should be in such a mental, physical and legal state as to be able exercise fully his power of choice.

It is obvious that $3 a$ is incompatible with $3 b$ an $\Phi$ the statements represent another example of a ça de beset by the tangle which is informed consent.

THE MRC CODE

In the 1960s various other bodies decided to try to help with the problem. The Medical Researci Council issued a report (1963) entitled 'Respons bility in investigations of human subjects.' Unde the section headed 'Procedures not of direct benefit to the individual' the statement is made thet 'the common feature of this type of investigation is. that it is of no direct benefit to the particula individual and that, in consequence, if he is to submit to it be must volunteer in the full sense of the word'. Three paragraphs later the statement is mades 'the situation in respect of minors and mentally subnormal or disordered persons is of particulas difficulty'. Now how does a minor or person who is mentally subnormal or mentally disordered 'volune teer' in the full sense of the word? That the com mittee found some difficulty in reconciling this problem is evident from their various paragraphs in the same section discussing consent. In the्ठ second paragraph it is stated:

'In investigations of this type it is, therefore, at ways necessary to ensure that the true consent of the subject is explicitly obtained.' The nexp paragraph continues ... 'by true consent is meant consent freely given with proper understanding of the nature and consequences of what is proposed'.

A little later in this section the following state ment is also made: 
'Above this age (12) the reality of any purported consent which may have been obtained is a question of fact and as with an adult the evidence would, if necessary, have to show that irrespective of age the person concerned fully understood the implications to himself of the procedures to which he was consenting.'

Despite these statements on consent the last paragraph starts as follows:

'Investigations that are of no direct benefit to the individual require, therefore, that his true consent to them should be explicitly obtained. After adequate explanation the consent of an adult of sound mind and understanding can be relied upon to be true consent.'

It is quite clear that the Council had severe problems with this section, and that the root of these problems was the attempt to ensure informed consent. Even the two attempts at defining it were markedly different.

In our own experiments we ensured that a full explanation was given. Furthermore, not only were our adults of 'sound mind and understanding', but all except four had medical or paramedical training or had formal training in first aid or had previously been volunteers. Some had had all three. Thus, although we fulfilled the requirements of the Medical Research Council's second and final definition of informed consent, we did not fulfil the requirements of their first.

\section{THE ROYAL COLLEGE OF PHYSICIANS CODE}

In 1973 the Royal College of Physicians published the findings of the Committee on the Supervision of the Ethics of Clinical Research Investigations in Institutions. This included, as an appendix, the report of the same Committee which was written in July 1967. Having said that the Declaration of Helsinki and the MRC report should guide clinical investigators in ethical practice they say that formal codes can 'only provide general guidance, and their application to specific problems must often remain a matter of opinion'. In the Committee's discussion on consent on page 2 of their report, it is stated that a full explanation should be given and that the agreement of the patient or subject should be recorded together with the signature of the "explainer' and his witness. No mention is made of understanding. This sidesteps the issues raised by the other codes.

\section{Can consent be 'informed'?}

The primary objective of the present work was to ascertain (using the investigator's global judgment) whether the consent obtained was 'informed' or not. It may be objected that such a judgment is too subjective to be of value. However, the fact is that in Britain at the present time judgments of this kind are made (or are supposed to be made) either by the investigator or by some other person holding responsibility (see the recommendations of the Royal College of Physicians, 1973, and of the Medical Research Council, 1963-64). Our study gave the research worker the opportunity of making a careful assessment of the consent he had already obtained. This method follows the spirit of Fletcher's (1974) principle: 'The principal investigator in each human study is charged with the responsibility to be the final judge of the quality of the consent obtained' (my italics).

A secondary objective was to ascertain if any failure was a failure to understand the 'nature of' or was it a failure to understand the "consequences of' possible risks. These objectives should not be confused with attempts to assess the impact of the information on the volunteers other than as stated above. Here the question was, "Are the volunteers informed?' The question, 'If not, why not?', would need a different type of investigation.

Our results appear to confirm the impression gained from the literature that informed consent is extraordinarily difficult to achieve; so much so as usually to be a practical impossibility in medically naïve subjects. We do not feel that devices such as 'the two-part consent form - a suggestion for promoting free and informed consent', described by Miller and Willner (1974), will help. It would appear that after a certain point has been reached in attempts to explain or clarify, the subject may 'switch off' and go into the 'we know you wouldn't hurt us doctor... ' routine. He could still answer the five-question questionnaire of Miller and Willner in such a way that 'informed' consent could be wrongly assumed to have been obtained. It is likely that truly informed consent is very rarely obtained from non-medical volunteer subjects and yet lip service continues to be paid to a practically impossible objective. This is highly dangerous, because, however conscientious the investigator and his witness might be during their early attempts to obtain informed consent, continuous attempting of the impossible will result in subconscious acknowledgement of the impossible and a token routine will take the place of genuine (but almost always unsuccessful) efforts to get the real thing. '.. beware of the path which leads to Nuremberg' (Garnham, 1971).

Most codes, whether written by individuals or committees, accept the fact that people can be legally competent or incompetent. They make provision for this fact and suggest that potential subjects who are legally incompetent have someone appointed to look after their interests. Why not do the same for people who are not medically competent? Whereas most of the adult population of the United Kingdom are considered legally competent, from the viewpoint of non-therapeutic clinical research they should be considered to be not medically competent and therefore should appoint 
a 'personal' doctor as a referee whose agreement to any study should be registered before the subject gives his voluntary consent. This doctor should be in a professional relationship to the potential subject, for example, the medical officer for student health for student volunteers, or the medical officer to the Post Office for post office workers, etc, or if the volunteer profers it he may ask his family doctor to help him. Thus a three-part system would be created: $a$ ) legal approval, $b$ ) medical approval, c) voluntary approval; $a$ ) and $b$ ), or $b$ ) and $c$ ) should be mandatory before a volunteer is included in a study. A full explanation should, of course, still be given to any subject by the investigator and all questions should be answered before the consent form is signed.

While it might be suggested that institutional ethical committees might be relied upon to ensure that high ethical standards are maintained, there are several possible disadvantages: I) The institutional ethical committee may be in danger of becoming a medico-legal committee instead, which primarily looks after the legal and financial interests of the institution. 2) A research programme may not arise in an institution. 3) In large cities the invidious situation may arise of different ethical concepts between different institutions. 4) Interpersonal problems may arise where a programme is disapproved.

It is suggested that the chance of these potential problems arising would be minimized if ethical committees were independent of institutions and were appointed on a geographical basis rather than by institutions.

\section{Conclusions}

The findings of this preliminary study cast serious doubt on the quality of consent likely to be obtained from subjects involved in non-therapeutic clinical research. In view of the difficulty found even by those with some medical knowledge in understanding possible consequences of experimental procedures, it seems that the phrase 'informed consent' has little or no meaning. It is suggested that by separating 'voluntary' from 'informed' consent, and that by introducing considerations of medical competence and approval, the ethical aims of the internationally accepted codes will be maintained. The appointment of ethical committees on a suprainstitutional rather than an institutional basis is also suggested.

\section{Acknowledgements}

The experimental work on which this paper is based was carried out in the Clinical Pharmacology Department of St Bartholomew's Hospital in conjunction with Professor E Shotton and $\mathrm{Mr} \mathrm{K}$ Raymond of the School of Pharmacy to whom grateful acknowledgement is made. I also gratefuly acknowledge the unstinted help and collaboration of Professor P Turner throughout this work.

\section{References}

American Medical Association (1959). Principles Medical Ethics. In F J L Blasingame (Ed), $18 \overline{40-}$ 1958. Digest of Official Actions of the Amerioan Medical Association. Chicago: American Medifgal Asscciation, 1959, p 232-237.

British Medical Association Booklet (1974). BMA House, Tavistock Square, London WCrH 9JP; Medical Ethics. p 2.

Beecher, H K, (1970). Research and the individutal human studies. Little, Brown and Company (inc) $\widehat{\mathrm{D}}$

Beecher's Code, (1966). Some guiding principles fồr clinical investigations. Fournal of the American Medical Association, 195, I135-1136.

Catholic Hospitals Association (1955). Selections from ethical and religious directives for catholic hospitalls related to experimentation on human subjects. 2nd ed St Louis: Catholic Hospitals Association. (D)

Daedalus (1969). Ethical aspects of experimentation wath human subjects. Fournal of the American Acade of Arts and Sciences.

Department of the Environment (1975). Personal communication.

Fletcher, J (1974). Documentation in Medical Ethic 4.

Food and Drug Administration (1966). Consent fer we of investigational new drugs on humans: staten of policy. Federal Regulation I1415, Aug 30 . Updated 1974.

Garnham, J C, Raymond, K. Shotton, E, and Turner $\mathscr{P}_{P}$ (1973). The effect of formulation on the avaifiability of sulphadiazine. Fournal of Pharmacy and Pharmacology, 25, 121-122.

Garnham, J C, Hicks, D C, Raymond, K, and Shottonon: (1973). Some observations on blood level data following oral administration of aspirin as table e्cts and capsules. British Fournal of Pharmacology, \$8, 336.

Garnham, J C, Raymond, K, Shotton, E, and TurneriP (1975). The effect of buffered aspirin on plasma indomethacin. European fournal of Clinical Pharmgcology, 8, 107-II3.

Garnham, P C C (1971). Progress in Parasitology. T娄e Athlone Press. $\mathrm{p}$ 125.

Hill, A B (1963). Medical ethics and controlled tridfy. British Medical fournal, 1, 1043-1049.

Harvard University Health Services (1963). Ru疋s governing the participation of healthy humfth beings as subjects in research. Formulated by the University Health Services and adopted by the President and Fellows on April $I$.

Miller, R, and Willner, H S (1974). The two-part consent form - A suggestion for promoting frge and informed consent. Nerw England Fournal off Medicine, 290, 964-966.

Medical Research Council, (1962-63). Report (Cm车 2382), pp 2I-25. HM Stationery Office. 
New York Academy of Sciences (1969). New dimensions in legal and ethical concepts for human research. Annals of the New York Academy of Sciences, 169, 293-593.

National Institutes of Health (1968). A code for selfexperimentation.

Nuremberg (1946-1949). Nuremberg Military Tribunal: US $\nabla \mathrm{K}$ Brandt et al.

Netherlands (1955). Report on human experimentation. Adopted by the Public Health Council of the Netherlands, 1957. World Medical fournal, 4, 299-300.

Royal College of Physicians (1973). Committee on the Supervision of the Ethics of Clinical Research Investigations in Institutions.

United States Army (1962). Army regulation no 70-25: Use of volunteers as subjects of research. Washington: Department of the Army.
United Nations (1958) Article 7. Draft covenant on civil and political rights. Adopted by the Third Committee of the General Assembly of the United Nations, 1958. Reaffirmed by the General Assembly, 1966.

World Medical Association (1949). International code of medical ethics. Adopted at General Assembly of World Medical Association, London, England, 1949. World Medical Association Bulletin, 1950.

World Medical Association (1948). Declaration of Geneva. The Second General Assembly of the World Medical Association, Geneva, Switzerland, Sept, 1948. World Metical Association Bulletin, 1949, I, 35-38.

World Medical Association (1964). Declaration of Helsinki. Recommendations guiding doctors in clinical research. Adopted by the World Medical Association in 1964 . 